ISSN 1810-3030 (Print) 2408-8684 (Online)

Journal of Bangladesh Agricultural University

Journal home page: http://baures.bau.edu.bd/jbau, www.banglajol.info/index.php/JBAU

\title{
Determinants of drought risk coping mechanisms among the farmers of Northern region of Bangladesh
}

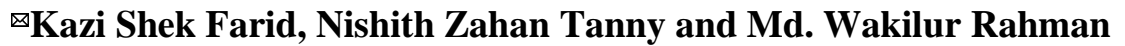

Department of Rural Sociology, Faculty of Agricultural Economics and Rural Sociology, Bangladesh Agricultural University, Mymensingh-2202, Bangladesh

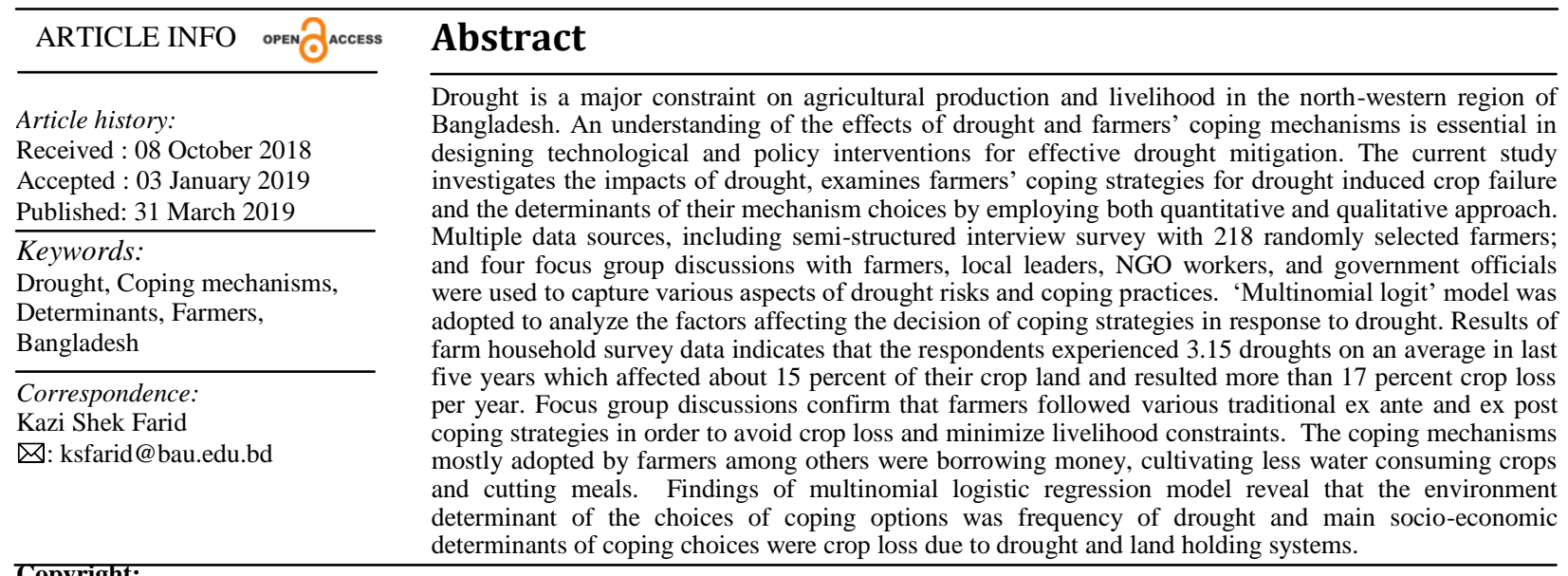

Copyright:

(c)

(C)2019 by authors and BAURES. This work is licensed under the Creative Commons Attribution International License (CC By 4.0).

\section{Introduction}

Changing climate pattern affects the livelihoods of people adversely in the developing world who are excessively dependent on the agricultural sector (IPCC, 2014 and IPCC, 2012). The negative consequences of natural disasters in the low-income countries range from material, economic, environmental losses to human development (UNISDR, 2008). The people have to tolerate the negative consequences of climate change not only because of their higher dependence on natural resources but also their inadequate capabilities to cope with the changing environment.

Bangladesh is one of the countries subjects to the devastating impacts of climate change and each year people of this country have to tolerate the devastating consequences of various natural disasters like flood, drought, river bank erosion, cyclones, etc. Besides other calamities, in Bangladesh, there exists a probability that 41 percent to 50 percent of land of the country experience drought in a year and there is also possibility to increase the intensity (IPCC, 2013).The nature and severity of disasters in different parts of Bangladesh vary and people of northern part of Bangladesh are experiencing severe drought but different dimensions of this incident remained unexplored yet (Farid, et al.,
2015). Literatures highlighting on negative impacts of drought ranged from agricultural perspectives to socioeconomic dimensions (Afroz and Rahman, 2013 and Paul, 1998). These include agricultural losses, income and asset disruption and the resultant social crises, etc. (Islam et al., 2014). However, farmers' response to the negative effects of drought on agriculture varies widely and alteration of coping mechanisms occurs depending on climatic conditions, farm types and other economic and institutional factors (Hisali et al., 2011; Reidsma $e t$ al., 2010). Similarly, to combat the crises, farmers of northern region employ different combinations of drought coping strategies. They usually adopt short-term responses to deal with the immediate impacts of droughts. These responses can be defined as proactive (anticipatory adaptation and psychological preparedness), made in anticipation of an event, or reactive, made after an event (Aspinwall, 2011). In the context of developing countries, coping strategies are generally the short-term responses to an immediate inaccessibility to food and these strategies largely refer to a set of measures to meet physiological, social, and economic needs of life (Richardson et al., 2011).Thus, addressing successful coping mechanisms in the context of global climate change requires a thoughtful consideration of prevention and preparedness (Ball, 2008). The unique nature of coping methods raises the 
necessity of the context and area specific study of drought mechanisms. So, the area and context specific documentation of survival mechanisms is necessary for development intervention.

Only a few studies have been conducted so far addressing factors influencing coping mechanisms due to climate induced drought in the northern part of Bangladesh. Literatures are found emphasizing on drought losses and the resultant adaptation priorities (Rawlani and Sovacool, 2011; Paul and Routray, 2011; Shahid and Behrawan, 2008). The identified adaptation options are water harvesting, water resource exploitation and crop intensification (Habiba et al., 2012). These adaptation priorities are not sufficient to capture the full picture of drought affected rural livelihoods. An understanding of farmers' coping mechanisms and inhibiting factors behind them will help to design more effective drought mitigation measures. Because, the factors that influence their coping decisions, especially by the resource-poor farmers need to be understood so that their drought mitigation plans can be enhanced properly. In this regard, present study aims to examine the drought coping mechanisms adopted by the farmers of the northern Bangladesh. In this paper, emphasize has been given on what coping strategies households employ before or after drought, and what determines the choice of coping strategies. The specific objectives are: to document drought experiences and its effects in the study area; to identify drought coping mechanisms adopted by the farmers; and to examine the influencing factors for adopting coping mechanisms by the farmers.

\section{Materials and Methods}

To examine the factors determining decision to drought mechanisms under climate change scenario in northern Bangladesh, two upazilas namely, Parbatipur under Dinajpur district and Sherpur under Bogura district were selected purposively for field inquisition since these sites are affected by climate change particularly by the drought (Habiba et al., 2011 and FAO, 2009). One union from each upazila was selected randomly. These unions were Boro Chandipur of Parbatipur and Garidaha of Sherpur upazila. After that, four villages from each union, i. e. total 8 villages namely Boro Chandipur, Chaitapara, Jharuardanga, and Kalikabaridanga from Boro Chandipur union and Ramnagar, Kanupur, Hatgari, and Bonga from Garidaha union were selected randomly. All the farmers of these eight villages were the population of the present study. In order to select the sample, a list of all farmers of the study villages were prepared first and then sampling frame was prepared accordingly. After that a list of sample farmers constituting a total of 264 farmers (129 from Parbatipur and 135 from Sherpur) was prepared taking approximately 10 percent and 15 percent of the population from each village by following simple random sampling. Then the farmers who were agreed and gave consent to participate in the survey during visit by the data enumerators become the final sample of the present study. Therefore, the actual sample size was 218 (108 from Parbatipur and 110 from Sherpur).

Data collection was carried out through interview survey based on a semi-structured pre-tested schedule, which means the main source of primary data was sample survey. Moreover, four focus group discussions (FGD) were also organized to get overall insights on the existing drought risk and associated coping options in the study areas. Various descriptive and inferential statistical techniques were applied for getting meaningful results. Furthermore, to investigate the coping decision in the study areas, multinomial logistic (MNL) model was adopted to see determinants of choosing different coping mechanisms. In order to determine the factors motivating farmers' choice of any or combination of coping mechanisms to climate induced drought, the probability model was used where the dependent variable is categorical. MNL model helps to capture the collective influence of different independent variables on the dependent variable. The dependent variable is discrete in nature with multiple choices, so the appropriate model for drought risk mechanism is MNL model (Legesse et al., 2013; Tessema et al., 2013). MNL model was used to determine the influence of explanatory variables on the choice of coping mechanisms to drought. The equation is as follows-

$$
P\left(y=\frac{j}{x}\right)=\frac{\exp \left(x \beta_{j}\right)}{\left[1+\sum_{h=1}^{j} \exp \left(x \beta_{h}\right), j=1 \ldots, J\right]}
$$

Where, $\beta_{j}$ is $\mathrm{K} \times 1, j=1, \ldots, J$.

\section{Results and Discussion}

Socio-economic characteristics of the study sample

Background characteristics of respondents are presented in Table 1 and Table 2. Agriculture was the primary occupation of 89 percent of the respondents followed by business ( 5 percent), service (4.6 percent), and other occupation (1.4 percent), respectively. Majority of farmers belonged to small to medium category farm. On an average, the farmers of the Parbatipur owned about 276 decimals of cultivable land, whereas this share was very low for the farmers of Sherpur owning only 93 decimals. As a result, most of the farmers (about 86 percent) of Sherpur were small farmers and about 42 percent farmers of Parbatipur were in medium category. The education level among farming population was low as about 18 percent were illiterate, 33 percent completed primary level education and only five percent were graduates. Average annual household income and expenditure of the farmers of studied upazilas were about Tk. 167.5 thousand and Tk. 118.5 thousand, respectively. 
Table 1. Distribution of respondents based on socio-economic characteristics

\begin{tabular}{llccc}
\hline Characteristics & Categories & $\begin{array}{c}\text { Parbatipur } \\
\text { (N=108) }\end{array}$ & $\begin{array}{c}\text { Sherpur } \\
(\mathrm{N}=110)\end{array}$ & Total (N=218) \\
\hline Level of education & Illiterate & $17(15.7)$ & $22(20)$ & $39(17.9)$ \\
& Primary & $25(22.2)$ & $48(43.6)$ & $72(33)$ \\
& Secondary & $48(44.4)$ & $33(30)$ & $81(37.2)$ \\
& Higher secondary & $12(11.1)$ & $3(2.7)$ & $15(6.9)$ \\
& Graduate & $7(6.5)$ & $4(3.6)$ & $11(5)$ \\
Occupation & Agriculture & $91(84.3)$ & $103(93.9)$ & $194(89)$ \\
& Business & $10(9.3)$ & $1(.9)$ & $11(5)$ \\
& Service & $5(4.6)$ & $5(4.5)$ & $10(4.6)$ \\
Training status & Other & $2(1.9)$ & $1(.9)$ & $3(1.4)$ \\
Land holdings (decimal) & percent of N & $44(40.7)$ & $20(18.2)$ & $64(29.4)$ \\
Average annual income ('000) & & 276 & 93 & 184.5 \\
Average annual expenditure ('000) & & 182 & 153 & 167.5 \\
\hline
\end{tabular}

Besides, the communication exposure was evaluated to get an insight on the possibility of getting agriculture related information from other people as well as from social media. Contact with various communication media like local leaders, dealers, and UAO, participation in agricultural related meeting and use of communication media was very low for the farmers of Sherpur compared to the farmers of Parbatipur which has been shown in Table 2 .

Table 2. Communication exposure (percentage of respondent)

\begin{tabular}{lcc}
\hline Categories of personnel/media & Parbatipur & Sherpur \\
Contact with local leaders & 89.8 & 36.4 \\
Contact with dealers & 89.8 & 66.4 \\
Contact with block supervisor & 77.8 & 49.1 \\
Contact with UAO & 43.5 & 2.7 \\
$\begin{array}{l}\text { Participation in agricultural related } \\
\text { meeting }\end{array}$ & 40.7 & 1.8 \\
$\begin{array}{l}\text { Attending result demonstration } \\
\text { meeting }\end{array}$ & 31.5 & 0.9 \\
$\begin{array}{l}\text { Watching agriculture related } \\
\text { programmes in radio/TV }\end{array}$ & 88.9 & 70.9 \\
\hline
\end{tabular}

The respondents of the study area maintain varied forms and ranges of communication with various important communication media. Communication scores were calculated based on these varied ranges of communication. The various ranges of communication included weekly, monthly, quarterly, and yearly communication with no communication as well. Communication scores range from 0-20. The communication score was categorized into four groups of equal range (dividing highest score 20 by 4). Communication score up to 5 indicates lower communication, whereas, scores 6-10 and 11-15 indicate medium and higher scores. Communication score above 15 implies very high communication. About 54 percent of the respondents at Sherpur were on communication score up to 5; on the other hand, only 11 percent of the respondents of Parbatipur were on this score. At Parbatipur, 35 percent of the respondents were on communication score 11 to 15 , whereas only 6 percent of the respondents were on this score at Sherpur.
More respondents at Parbatipur were on communication score more than 15; on the other hand, at Sherpur this was negligible. In total, highest 39 percent of the respondents were in medium category and only about 9 percent of the respondents were in very high category of communication (Table 3). Moreover, the chi-square value is significant at 10 percent level of significance, which indicates that there was a significant difference in the extent of communication among the farmers of two region.

Table 3. Distribution of the respondents based on the extent of communication

\begin{tabular}{|c|c|c|c|c|}
\hline \multirow{2}{*}{$\begin{array}{l}\text { Extent of } \\
\text { communication } \\
\text { (score) }\end{array}$} & \multicolumn{2}{|c|}{ Upazila } & \multirow{2}{*}{ Total } & \multirow{2}{*}{$\begin{array}{l}\text { Pearson } \\
\text { Chi-Square }\end{array}$} \\
\hline & Parbatipur & Sherpur & & \\
\hline Low (Up to 5) & $12(11.1)$ & 59 (53.6) & 71 (32.6) & \\
\hline Medium $(6-10)$ & $40(37.0)$ & 45 (40.9) & $85(39.0)$ & 71.931* \\
\hline $\operatorname{High}(11-15)$ & $38(35.2)$ & $5(4.5)$ & 43 (19.7) & \\
\hline $\begin{array}{l}\text { Very high } \\
(15-20)\end{array}$ & $18(16.7)$ & $1(0.9)$ & $19(8.7)$ & \\
\hline
\end{tabular}

Note: Figures in the parentheses indicate percentage

\section{Drought and its effect}

Drought is a recurrent phenomenon in the northern Bangladesh. Table 4 shows the distribution of respondents based on drought experience. 45 percent of total respondents experienced drought almost 3 times during lastfive-year period. Besides, about 28.5 percent of the respondents had to go through 4-5 times drought during this period. On the contrary, only 3.2 percent of total respondents experienced single drought in afiveyear time period. So, it can be deduced that drought is a common phenomenon in this area and this finding is also supported by the study of Habiba et al.(2011) who also mentioned that the studied areas are drought-prone.

Table 4. Frequency of drought during five-year period

\begin{tabular}{cccccc}
\hline $\begin{array}{c}\text { Frequency } \\
\text { of drought }\end{array}$ & Parbatipur & Sherpur & Total & Mean & $\begin{array}{c}\text { Std. } \\
\text { deviation }\end{array}$ \\
\hline 1 & 0.9 & 5.5 & 3.2 & & \\
2 & 3.7 & 42.7 & 23.4 & & \\
3 & 61.1 & 29.1 & 45.0 & 3.15 & 1.055 \\
4 & 10.2 & 14.5 & 12.4 & & \\
5 & 24.1 & 8.2 & 16.1 & & \\
\hline
\end{tabular}


About 26 percent of the respondents at Sherpur reported that no land was affected by drought, whereas the percentage of respondents reporting the same was about 7.4 at Parbatipur. At Parbatipur, almost 30 percent of the respondents said that 21 to 30 percent land area was affected by drought; on the other hand, 23 percent of the respondents mentioned it at Sherpur. Besides, about 4 and 26 percent of total respondents said that more than 30 percent and 21-30 percent of their land was affected by drought, respectively (Table 5).That means, almost 30 percent of the respondents reported that more than 20 percent of their lands were affected by drought. They incurred severe losses due to frequent droughts.

Table 5. Percentage distribution of respondents based on land area affected by drought

\begin{tabular}{cccc}
\hline Percentage of land area & \multicolumn{2}{c}{ Upazila } & Total \\
\cline { 2 - 3 } & Parbatipur & Sherpur & \\
\hline 0 & 7.4 & 25.5 & 16.5 \\
$1-10$ & 26.9 & 21.8 & 24.3 \\
$11-20$ & 32.4 & 26.4 & 29.4 \\
$21-30$ & 29.6 & 22.7 & 26.1 \\
$30+$ & 3.7 & 3.6 & 3.7 \\
Total & 100.0 & 100.0 & 100.0 \\
\hline
\end{tabular}

Drought has negative impact on crop production. In Sherpur, more than 30 percent of the respondents mentioned that there was no crop loss in case of drought, whereas Parbatipur showed different phenomena. At Parbatipur, 28 percent of the respondents mentioned about 21 to 30 percent crop loss due to drought; on the other hand, this figure is 14 percent in case of Sherpur. The respondents of Parbatipur experienced twice crop loss compared to Sherpur. As a whole, 17 percent of the respondents of two areas lost more than 30 percent of their crop. About four-fifths of the respondents experienced crop loss to some extent. Moreover, the significant value of chi-square at 10 percent level of significance indicates the significant difference in crop loss between Parbatipur and Sherpur. The percentage distribution of farmers based on crop loss experiences due to drought is shown in Table 6.

Table 6. Percentage distribution of farmers based on crop loss due to drought

\begin{tabular}{ccccc}
\hline Percent of & \multicolumn{2}{c}{ Upazila } & Total & $\begin{array}{c}\text { Pearson } \\
\text { crop loss }\end{array}$ \\
\cline { 2 - 3 } & Parbatipur & Sherpur & & Chi-Square \\
\hline 0 & 5.6 & 30.9 & 18.3 & \\
$1-10$ & 18.5 & 32.7 & 25.7 & \\
$11-20$ & 16.7 & 20.0 & 18.3 & $55.531^{*}$ \\
$21-30$ & 27.8 & 13.6 & 20.6 & \\
$30+$ & 31.5 & 2.7 & 17.0 & \\
Total & 100.0 & 100.0 & 100.0 & \\
\hline
\end{tabular}

\section{Drought risk coping mechanisms}

Respondents in the study areas have developed various survival mechanisms to cope with problems of drought. The higher dependence on agriculture, illiteracy and poor economic condition forces farmers to take mechanisms just to face immediate losses. The various mechanisms adopted by the farmers to cope with the effects of drought were categorized into ex ante and ex post mechanisms. Traditional local Ex ante mechanisms were adopted before the occurrence of drought in order to cope with this climatic event, which were helpful to reduce risk. These mechanisms included along with others diversification of agricultural enterprises, diversification of production activities, crop diversification, switching from farm to non-farm activities, varietal selection, planting various crops in separate plots, adjustment of allocated crop area depending on the climatic conditions, postpone or adjust timing of crop planting, etc. On the other hand, ex post mechanisms were adopted for reducing the impact of risk after the drought has occurred. The important ex post mechanisms were cutting down expenditure, migration of one or more family members, consumption loans, consuming less, asset liquidation, reliance on charity, loans from non-economic organizations, etc. Respondents who were exposed to drought risk used one or more strategies in different combinations to ensure their survival. Some of these strategies like selecting less water consuming varieties were incorporated into the nature of the farming system over a long period of time. Some others were employed only under certain risky situation that is just after the occurrence of drought.

For this study, six coping strategies, which were important according to the participants and most widely adopted by them, were separated for further statistical analysis. These strategies were separated based on the perceptions of the participants discussed during the focus group discussions. These were leaving lands fallow, cultivating less water consuming crops, borrowing money from others, migration of family members, working as laborers in others' farm and cutting meals. The distribution of farmers by their choices of coping mechanisms presented in Table 7 reveals that a larger proportion (67.0 percent) of the farmers preferred borrowing money as a coping method to combat drought; followed by cultivating less water consuming crops and cutting meals by 49.1 percent of the respondents in both cases. However, migration of family members (16.1 percent) and work as laborer in other's farm (25.2 percent) were the least preferred coping measures by the farmers. The percentage of respondents who cultivate less water consuming crops was higher (64.4 percent)at Parbatipur than at Sherpur (33.6 percent). On the other hand, borrowing money at Parbatipur was double than at Sherpur. Involvement of the respondents to others' farms as labourer was higher in Parbatipur, approximately two times than that of Sherpur. The more respondents of Parbatipur had to work to others' farms as laboureres and borrow money in order to meet their basic needs. The adoption of survival mechanisms was higher for Parbatipur because the severity of drought was higher at Parbatipur than Sherpur. 
Table 7. Survival mechanisms adopted by the respondents (percentage of households)

\begin{tabular}{|c|c|c|c|c|c|c|}
\hline \multirow[t]{2}{*}{ Mechanism } & \multicolumn{2}{|c|}{ Parbatipur } & \multicolumn{2}{|c|}{ Sherpur } & \multicolumn{2}{|c|}{ Total } \\
\hline & Yes & No & Yes & No & Yes & No \\
\hline $\begin{array}{l}\text { Leave the la } \\
\text { fallow }\end{array}$ & 27.8 & 72.2 & 26.4 & 73.6 & 27.1 & 72.9 \\
\hline $\begin{array}{l}\text { ate less water } \\
\text { ming crops }\end{array}$ & 64.8 & & 33.6 & 66.4 & 49.1 & 50.9 \\
\hline Borr & 89.8 & & 44.5 & 55.5 & 67.0 & 33.0 \\
\hline $\begin{array}{l}\text { Migr } \\
\text { mem }\end{array}$ & 20.4 & 79.6 & 11.8 & 88.2 & 16.1 & 83.9 \\
\hline $\begin{array}{l}\text { Work as laborers in } \\
\text { others' farm }\end{array}$ & 33.3 & 66.7 & 17.3 & 82.7 & 25.2 & 74.8 \\
\hline Cutting meals & 53.7 & 46.3 & 44.5 & 55.5 & 49.1 & 50.9 \\
\hline
\end{tabular}

Factors responsible for farmers' coping mechanisms decisions

There exists variation among drought affected respondents on frequency of adoption of drought coping mechanisms. Respondents' socio-economic status and environmental exposure led them to undertake different coping mechanisms during drought. Fig. 1 indicates that mean mechanism score was 2.32 with a standard deviation of 1.363. It implies that majority of the farmers usually adopted more than one mechanism and this range was between 2 to 3 . The total percentage of farmers was 49.5 who employed 2 or 3 coping mechanisms (Table 8).

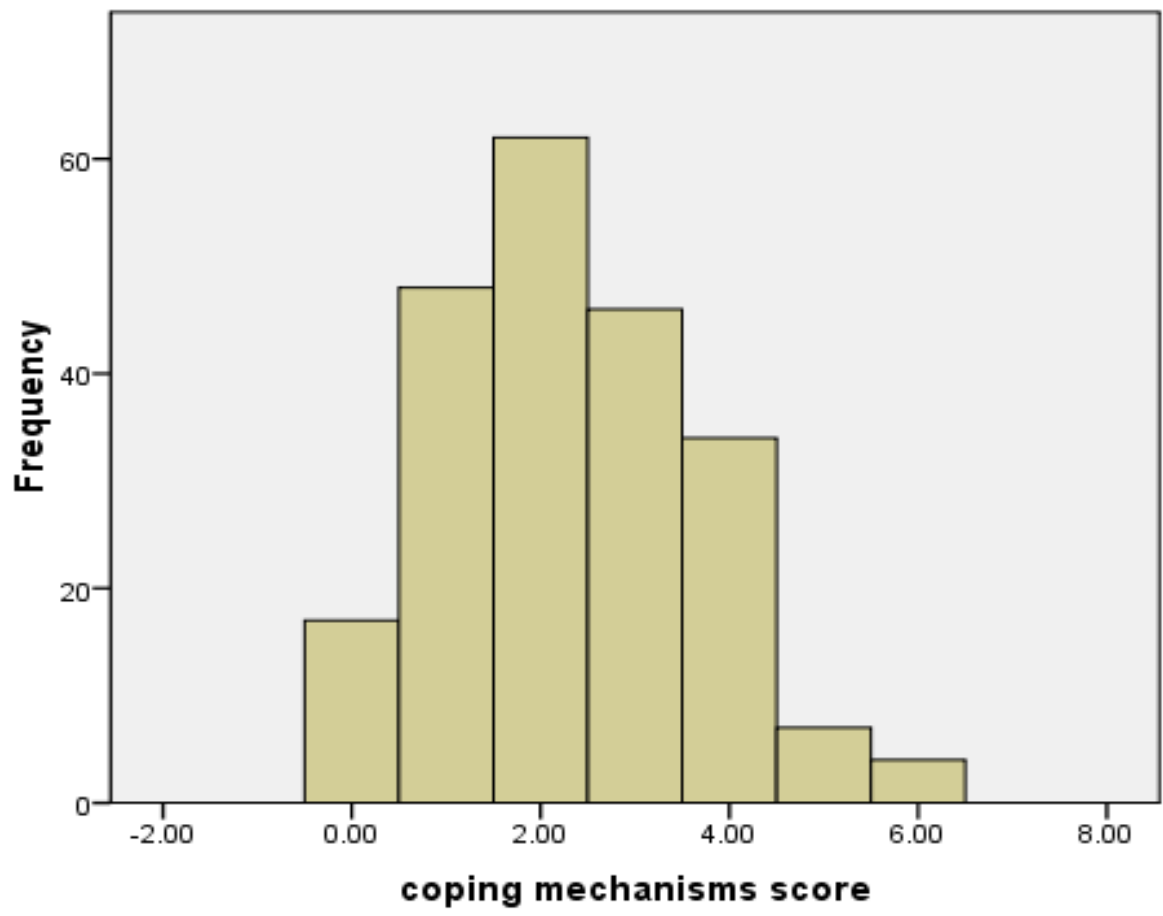

Mean $=2.32$

Std. Dev. $=1.363$

$\mathbf{N}=\mathbf{2 1 8}$

Fig. 1. Coping mechanism score

Table 8. Distribution of farmers based on frequency of mechanism adoption

\begin{tabular}{cccc}
\hline $\begin{array}{c}\text { No. of } \\
\text { mechanisms }\end{array}$ & $\begin{array}{c}\text { Frequency } \\
\text { of adoption }\end{array}$ & $\begin{array}{c}\text { Percentage } \\
\text { of farmers }\end{array}$ & $\begin{array}{c}\text { Cumulative percentage } \\
\text { of farmers }\end{array}$ \\
\hline 0 & 17 & 7.8 & 7.8 \\
1 & 48 & 22.0 & 29.8 \\
2 & 62 & 28.4 & 58.3 \\
3 & 46 & 21.1 & 79.4 \\
4 & 34 & 15.6 & 95.0 \\
5 & 7 & 3.2 & 98.2 \\
6 & 4 & 1.8 & 100.0 \\
\hline
\end{tabular}

Multinomial logistic (MNL) model was adopted to see determinants of choosing different coping mechanisms. The dependent variable for MNL model used in this study was respondents' decision on coping options due to drought. The alternative drought risk strategies included leave the lands fallow, cultivate less water consuming crops, borrowing money, migration of family members, working as laborers in others' farm and cutting meals. For simplicity, the coping options were divided into three categories, namely, adopting no mechanism, adopting 1 to 3 mechanisms and adopting more than 3 mechanisms. Thus, the dependent variable in the model was a categorical variable taking a discrete value of 1,2 , and 3 representing the above choices. Independent variables determine whether or not a respondent takes some mechanism to cope with the drought impact. Table 9 illustrates the results of MNL models showing the probability of choosing any of the three options. The base category was respondents' decision of adopting more than 3 mechanisms. The odds ratio of land holding is 2.780 , which implies that a unit increase in land holding increases the probability of a respondent to shift from the category of adopting more than three mechanisms to adopting no mechanism category by 178 percent. The reason may be that most of the options available to respondents were related to 
coping mechanisms not adaptation options. Large farmers were more able to cope with drought with their existing solvency without adopting any income or consumption smoothing option. At the same time, a unit increase in the crop loss due to drought decreases the probability of a respondent to adopt no mechanism by 12.30 percent. This result also supports the previous argument.

A unit increase in the frequency of drought decreases the probability of a respondent to shift from adopting more than 3 mechanisms to adopting only 1 to 3 mechanisms by 93.11 percent. Because when the frequency of drought increases then respondents needed to take several survival mechanisms and most often they are bound to adopt more than three existing coping mechanisms. Similarly, one unit increase in crop loss due to drought decreases the probability of using 1 to 3 mechanisms to more than 3 mechanisms by 3.7 percent. It is clear that respondents were forced to undertake several mechanisms and they did so when they had no other options remained. For instance, when they had inadequate amount of land to support them during crises, they took such techniques to regularize consumption and income to certain extent. On the contrary, when they could tackle the situation without such adjustments, they preferred to do so. For example, respondents who had larger amount of land could apply modern techniques effectively to combat drought. These techniques might take in the forms of using drought tolerant varieties to use better irrigation practices. They did not need to take the given traditional coping mechanisms rather they could choose different adaptation options. At the same time, the larger land holdings might increase the probability of lands that might be remained safe in times of drought.

Table 9. Results of multinomial logistic model

\begin{tabular}{lcccccc}
\hline Independent variables & \multicolumn{3}{c}{ Adopting no mechanism } & \multicolumn{3}{c}{ Adopting 1 to 3 mechanisms } \\
\cline { 2 - 7 } & $\beta$ & S.E. & Odds Ratio & $\beta$ & S.E. & Odds Ratio \\
\hline Intercept & .921 & 1.397 & & $2.961^{* * *}$ & .850 & .689 \\
Frequency of drought & -.459 & .335 & .689 & $-.440^{* *}$ & .190 & .047 \\
Communication score & -.113 & .092 & .854 & .004 & .047 & 1.038 \\
Land holding & $1.005^{* *}$ & .430 & 2.780 & .336 & .251 & 1.465 \\
Education & .263 & .383 & 1.396 & .186 & .234 & 1.283 \\
Training & .111 & .527 & 1.120 & .055 & .296 & 1.024 \\
Crop loss due to drought & $-.168^{* * *}$ & .042 & .877 & $-.068^{* * *}$ & .014 & .963 \\
\hline
\end{tabular}

Note: The reference category is adopting more than 3 mechanisms. $* * p<0.05$ and $* * * p<0.01$ are the levels of significance. $\beta$ denotes regression coefficient and S.E. denotes standard error of the regression coefficient.

\section{Conclusion}

The study sought farmers' existing drought coping strategies and inhibiting factors behind such mechanisms in northern Bangladesh. It is evident from the results of the study that drought coping mechanisms were mainly short-term responses to face the immediate circumstances. Recurrent drought resulted in disruption of production which acted as an exerting force to develop and adopt coping mechanisms to recover from drought. These were still mostly the traditional coping mechanisms including leaving lands fallow, borrowing money and eating fewer amounts, etc. However, as the drought's frequency and severity are anticipated to enlarge in near future, so these traditional coping mechanisms will no longer be adequate for meeting the emerging challenges. This inference is also similar with Pandey et al. (2007). The results of multinomial logit (MNL) model portray that the possibility of farmers' decision of confining to just 1 to 3 coping mechanisms rather than adopting more than 3 traditional mechanisms were influenced negatively by both frequencies of drought and crop loss due to drought. At the same time, land holding has positive influence on taking no such traditional mechanism in contrast with adopting more than 3 mechanisms. Because farmers who have sufficient amount of land were solvent enough and they did not need to adopt the survival mechanisms immediately to cope with drought. Besides, large rich farmers can think about possible adaptation priorities for future which can be a tough choice for small and marginal poor farmers. We can, therefore, conclude that small and marginal farmers are more susceptible to drought risks and the subsequent losses. Further study needs to be done in exploring small and marginal poor farmers' coping strategies more rigorously so as to design more comprehensive policies for helping those farmers effectively. Policies should support land holdings of farmer which is expected to resolve consumption as well as income crises during and after drought in the long run through bringing more effective adaptation practices. Similarly, the modern and sustainable adaptation options should be available to farmers. Thus, it will help the resource poor farmers to reduce the economic, social and environmental losses of drought.

\section{References}

Afroz, R. and Rahman, M. A. 2013. Transboundary river water for Ganges and Teesta rivers in Bangladesh: An assessment. Global Science and Technology, 1: 100-111.

Aspinwall, L. G. 2011. Future-oriented thinking, proactive coping, and the management of potential threats to health and wellbeing. In S. Folkman (ed.).The Oxford handbook of stress, health and coping, pp. 334-365. New York: Oxford University Press.

Ball, T.F. 2008. Climate change: Dangers of a singular approach and consideration of a sensible strategy. Energy and Environment, 20(1): 201-205. 
https://doi.org/10.1260/095830509787689187

Farid, K.S., Tanny, N.Z.,Sarma, P.K. 2015. Factors affecting adoption of improved farm practices by the farmers of Northern Bangladesh. Journal of the Bangladesh Agricultural University, 13(2):291-298.

https://doi.org/10.3329/jbau.v13i2.28801

Food and Agriculture Organization (FAO). 2009. Profile for climate change. Rome, Italy. p.28.

Habiba, U., Shaw, R. and Takeuchi, Y. 2011. Socio-economic impact of droughts in Bangladesh. In R. Shaw and H. Nguyen (eds.). Droughts in Asian monsoon region. Bingley: Emerald Group Publishing Limited, pp. 25-48. https://doi.org/10.1108/S2040-7262(2011)0000008008

Habiba, U., Shaw, R. and Takeuchi,Y. 2012. Farmers' perception and adaptation practices to cope with drought: Perspectives from northwestern Bangladesh. International Journal of Disaster Risk Reduction, 1(1): 72-84. https://doi.org/10.1016/j.ijdrr.2012.05.004

Hisali, E., Birungi, P. and Buyinza, F. 2011. Adaptation to climate change in Uganda: Evidence from micro level data. Global Environmental Change, 21(4): 1245-1261. https://doi.org/10.1016/j.gloenvcha.2011.07.005

IPCC. 2012. Managing the risks of extreme events and disasters to advance climate change adaptation. In C.B. Field, V. Barros, T.F. Stocker, Q. Dahe, D.J. Dokken, K.L. Ebi, M.D. Mastrandrea, K.J. Mach, G.K. Plattner, S.K. Allen, M. Tignor, and P.M. Midgley (eds.). Special Report of the Intergovernmental Panel on Climate Change.Cambridge: Cambridge University Press. https://doi.org/10.1017/CBO9781139177245

IPCC. 2013. Climate Change 2013: The physical science basis. Contribution of Working Group I to the Fifth Assessment Report of the Intergovernmental Panel on Climate Change. Cambridge: Cambridge University Press.

IPCC. 2014. Climate Change 2014: Impacts, adaptation, and vulnerability. In C.B. Field, V. Barros, D.J. Dokken, K.J. Mach, M.D. Mastrandrea, T.E. Bilir, M. Chatterjee, K.L. Ebi, Y.O. Estrada, R.C. Genova, B. Girma, E.S. Kissel, A.N. Levy, S. MacCracken, P.R. Mastrandrea, and L.L. White (eds.). Report of the Intergovernmental Panel on Climate Change.Cambridge: Cambridge University Press. https://doi.org/10.1017/CBO9781107415379

Islam, A.R.M.T., Tasnuva, A., Sarker, S.C., Rahman, M.M., Mondal, M.S.H. and Islam, M.M.U. 2014. Drought in northern Bangladesh: Social, agro ecological impact and local perception. International Journal of Ecosystem, 4(3): $150-158$.
Legesse, B.,Ayele, Y. and Bewket, W. 2013. Smallholder farmers' perceptions and adaptation to climate variability and climate change in Doba district, West Hararghe, Ethiopia. Asian Journal of Economic and Empirical Research, 3(3): 251-265.

Pandey, S., Bhandari, H., Ding, S. and Sastri, A. 2007. Coping with drought in rice farming in Asia: Insights from a crosscountry comparative study. Agricultural Economics, 37 (s1): 213-224. https://doi.org/10.1111/j.1574-0862.2007.00246.x

Paul, B.K. 1998. Coping mechanisms practiced by drought victims (1994/5) in North Bengal. Bangladesh Applied Geography, 18 (4): 355-373. https://doi.org/10.1016/S0143-6228(98)00026-5

Paul, S.K. and Routray, J.K. 2011. Household response to cyclone and induced surge in coastal Bangladesh: Coping strategies and explanatory variables. Natural Hazards, 57 (2): 477-499. https://doi.org/10.1007/s11069-010-9631-5

Rawlani, A.K. and Savacool, B.K. 2011.Building responsiveness to climate change through community-based adaptation in Bangladesh. Mitigation and Adaptation Strategies for Global Change, 16:845-863. https://doi.org/10.1007/s11027-011-9298-6

Reidsma, F., Ewert, A.O. and Lansink, R. L. 2010. Adaptation to climate change and climate variability in European agriculture: The importance of farm level responses. European Journal of Agronomy, 32: 91-102. https://doi.org/10.1016/j.eja.2009.06.003

Richardson, A.E., Hadobas, P., Hayes, J.E., O'Hara, C.P. and Simpson, R.J. 2001.Utilization of phosphorus by pasture plants supplied with myo-inositol hexaphosphate is enhanced by the presence of soil microorganisms. Plant and Soil, 229(1): 47-56. https://doi.org/10.1023/A:1004871704173

Shahid, S. and Behrawan, H. 2008. Drought risks assessment in the Western part of Bangladesh. Journal of the International Society for the Prevention and Mitigation of Natural Hazards, 46(3): 391-413. https://doi.org/10.1007/s11069-007-9191-5

Tessema, Y.A., Aweke, C.S. and Endris, G.S. 2013.Understanding the process of adaptation to climate change by small-holder farmers: The case of east Hararghe Zone, Ethiopia. Agricultural and Food Economics, 1: 13. https://doi.org/10.1186/2193-7532-1-13

UNISDR. 2008. United Nations International Strategy for Disaster Reduction Secretariat. Briefing note 01: Climate change and disaster risk reduction, International Environment, Geneva. 